\title{
Cyclosporin A inhibits apolipoprotein Al gene expression
}

\author{
Xi-Long Zheng and Norman C W Wong \\ Department of Biochemistry and Molecular Biology, University of Calgary, 3330 Hospital Drive NW, Calgary, Alberta, Canada T2N 4N1 \\ (Requests for offprints should be addressed to X-L Zheng; Email: xlzheng@ucalgary.ca) \\ (X-L Zheng is a recipient of the new investigator award from the Heart \& Stroke Foundation of Canada)
}

\begin{abstract}
Cyclosporin A (CsA), a calcineurin inhibitor, has been widely used as an immunosuppressant, and is known to induce hyperlipidemia and dyslipoproteinemia with low levels of high-density lipoprotein (HDL). Since apolipoprotein Al (apo Al) is a major protein component of HDL particles and reduction of apo Al results in low levels of HDL, we hypothesized that CsA inhibits apo Al gene expression contributing to its lipid effects. Therefore, we first measured the serum apo Al protein levels in rats with or without CsA treatment, and found that both serum apo Al protein and liver apo AI mRNA levels were significantly reduced in response to CsA treatment. In stably transfected Hep G2 cells harboring an apo Al-474-CAT reporter gene, we found that intracellular calcium mobilization by A23187 a calcium ionophore stimulated apo Al gene expression and the calcineurin inhibitors, CsA and FK605, selectively inhibited this stimulation. Therefore, we conclude that activation of the calcineurin pathway by intracellular calcium mobilization stimulates apo Al gene expression and calcineurin inhibition by CsA results in reduced apo $\mathrm{Al}$ gene expression.
\end{abstract}

Journal of Molecular Endocrinology (2006) 37, 367-373

\section{Introduction}

Apolipoprotein AI (apo AI) is the major protein component in high-density lipoprotein (HDL) particles, which possess antiatherogenic properties (Brouillette \& Anantharamaiah 1995, Andersson 1997). As a cofactor, apo AI enhances the activity of lecithin cholesterol acyltransferase, which promotes 'reverse cholesterol transport' (RCT; Dobiasova \& Frohlich 1998), whereby cholesterol is transported from extra-hepatic cells to the liver for excretion in the form of bile salts or free cholesterol (Miller et al. 1985, Barter \& Rye 1996b). Therefore, increased RCT lowers total cholesterol (Fielding \& Fielding 1995), and apo AI levels inversely correlate to the incidence of atherosclerotic cardiovascular diseases (Rubin et al. 1991, Barter \& Rye 1996a, Luoma 1997). Owing to the pivotal role of apo AI in the functions of HDL particles, it is critical to identify mechanisms underlying either stimulation or inhibition of apo AI gene expression.

It has been of interest to many laboratories, including our own, to investigate hormonal control of apo AI expression and address how thyroid hormone, glucocorticoids, estradiol, androgens, retinoic acid, and insulin modulate activation of the gene (Soyal et al. 1995, Murao et al. 1998, Ness et al. 1998, Hargrove et al. 1999). These hormones, except insulin, stimulate intracellular receptors that act within the nucleus. However, our previous studies have indicated that the activation of protein kinase A (PKA) and protein kinase $\mathrm{C}$ (PKC) also stimulates apo AI gene expression through the Sp1-transcription factor and the insulinresponsive core element (Murao et al. 1998, Zheng et al. 2000, 2001). These studies suggest that the apo AI gene could be regulated by various growth factors and hormones in vivo and the clinical drugs that modulate the intracellular signaling network may also regulate apo AI gene expression.

Cyclosporin A (CsA) is an inhibitor of calcineurin, a calcium/calmodulin-activated protein phosphatase (Klee et al. 1998), and has been widely used as an immunosuppressant in organ transplant patients. One of the side effects of CsA is hyperlipidemia (Ballantyne et al. 1989), in which total cholesterols are high, and HDL and apo AI levels are low. It has been proposed in a mouse model that CsA causes dyslipoproteinemia through selective activation of sterol-regulatory element-binding protein-2, which leads to enhanced expression of lipid metabolism genes and hepatic secretion of VLDL triglyceride (Wu et al. 1999). In addition, CsA is reported to inhibit ABCA1-dependent cholesterol efflux with reduced HDL levels in mice (Le Goff et al. 2004). Therefore, it is also possible that CsA reduces serum apo AI to lower HDL levels (Lopez-Miranda et al. 1992, Kuster et al. 1994). To date, it is not known whether CsA inhibits apo AI gene expression, leading us to the studies in this report. Our results showed that CsA inhibited gene expression of apo AI in vivo. Additionally, in stably transfected Hep G2 cells harboring an apo AI-474-CAT (chloramphenicol acetyltransferase) reporter gene, CsA inhibited apo AI gene expression induced by intracellular calcium mobilization. 


\section{Materials and methods}

\section{Materials}

Male Sprague-Dawley (SD) rats $(\sim 350 \mathrm{~g})$ were purchased from Charles River Laboratories (Saint Constant, QC, Canada). The animal study protocol was approved by the Animal Use and Care Committee at the University of Calgary. Human hepatoma, Hep G2, cells were purchased from the American Type Culture Collection. CsA and FK506 were purchased from Sigma-Aldrich. The pAI.474-CAT plasmid was constructed using PCR and rat genomic DNA as the template as previously described (Romney et al. 1992).

\section{Animal treatment with CsA}

Five rats were included in each group. Rats were s.c. injected with CsA (20 mg/kg per day) or olive oil (vehicle alone) for 7 days (Wu et al. 1999). Animals were then killed, and whole blood was collected for serum apo AI protein measurement. Liver tissues were sampled for apo AI mRNA detection.

\section{SDS-PAGE and western immunoblots}

An aliquot of each serum sample was separated by electrophoresis in 10\% SDS-polyacrylamide gels and transferred to polyvinylidene difluoride membrane (Millipore, Waters Corp., Bedford, MA, USA). Apo AI protein was identified using a monoclonal antibody (Calbiochem, Hornby, Ontario, Canada) and the signal was detected using ECL reagents (Amersham Pharmacia Biotech) as previously described (Gui \& Zheng 2003).

\section{RNA preparation, reverse transcription (RT)-PCR and northern blotting}

Liver tissues were homogenized using a polytron homogenizer and total RNA was extracted using TRI reagent (Molecular Research Center, Cincinnati, OH, USA). RNA was reverse transcribed with a first-strand cDNA synthesis kit using a pd $(\mathrm{N})_{6}$ primer (Amersham Pharmacia Biotech) according to the manufacturer's protocol. Three microliters of this solution were amplified using PCR with a primer pair (forward: 5'-GATGAAAGCTGCAGTGTTGGCTGT-3'; reverse: $5^{\prime}$-TCCTGTAGGCGACCAACAGTTGAA-3') designed from the rat apo AI gene (GI:55746). The number of PCR cycles used (35 cycles of a primer extension period of $1 \mathrm{~min}$ at $72^{\circ} \mathrm{C}$ ) was within the linear range for the PCR signals yielded for apo AI. RT-PCR signals of $255 \mathrm{bp}$ fragments from apo AI mRNA transcripts were normalized with the signals obtained from glyceraldehyde-3-phosphate dehydrogenase (GAPDH; Zheng et al. 2000). The mRNA levels were then determined using northern blotting analysis as we previously described (Murao et al. 1998).

\section{Cell culture and treatment}

Hep G2 cells have previously been used by ourselves and others for studying both signaling pathways and apo AI expression (Herbomel et al. 1984, Murao et al. 1998, Sakai et al. 2000). Cells were maintained in Dulbecco's modified Eagle's medium (Life Technologies, Inc.) supplemented with $10 \%$ bovine calf serum (Life Technologies, Inc.) and penicillin/streptomycin and cultured at $37^{\circ} \mathrm{C}$ in $5 \% \mathrm{CO}_{2}$. Cells were cultured overnight in serum-free medium $(0 \%$ fetal bovine serum) prior to addition of the agent(s) of interest. Times for treatment with various drugs are indicated in the figure legends.

\section{Stable transfection and CAT activity assay}

Hep G2 cells were transfected using LipofectAMINE (Life Technologies, Inc.). Stably transfected Hep G2 cells were created by cotransfecting the plasmids pAI.474-CAT and pRc/CMV2 (Invitrogen) that carries neomycin resistance. Single colonies that grew in media containing $400 \mu \mathrm{g} / \mathrm{ml}$ geneticin (G418) were assayed for CAT activity as previously described (Romney et al. 1992, Murao et al. 1998, Zheng et al. 2001). The positive colonies were selected for further studies as previously described (Zheng et al. 2000, 2001).

\section{Calcineurin phosphatase activity assay}

To measure the phosphatase activity of calcineurin, cultured cells were lysed by repeated freezing and thawing in lysis buffer $(50 \mathrm{mM}$ Tris- $\mathrm{HCl}(\mathrm{pH} 7 \cdot 5)$, $0.1 \mathrm{mM}$ EGTA, $1 \mathrm{mM}$ EDTA, $0.5 \mathrm{mM}$ dithiothreitol (DTT), $0 \cdot 3 \mathrm{mM}$ phenylmethylsulfonyl fluoride, $0 \cdot 1 \%$ CHAPS, $50 \mu \mathrm{g} / \mathrm{ml}$ soybean trypsin inhibitor, $5 \mu \mathrm{g} / \mathrm{ml}$ leupeptin, and $5 \mu \mathrm{g} / \mathrm{ml}$ aprotinin). The calcineurin activity was determined photometrically $(630 \mathrm{~nm})$ at $30^{\circ} \mathrm{C}$ after using the RII phosphopeptide substrate (150 $\mu \mathrm{M}$, Calbiochem) as previously described (Dunn et al. 2000). Essentially, $30 \mu \mathrm{l}$ cell lysates were mixed with $20 \mu \mathrm{l}$ reaction solution containing $40 \mathrm{mM}$ Tris $(\mathrm{pH} \mathrm{8})$,

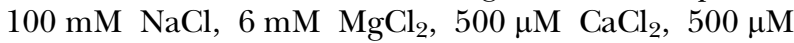
DTT, $750 \mathrm{nM}$ okadoic acid, $150 \mu \mathrm{M}$ peptide, $3 \mu \mathrm{M}$ calmodulin, and incubated for $30 \mathrm{~min}$ at $30^{\circ} \mathrm{C}$ in the presence or absence of CsA, FK605, or rapamycin. The detection of released phosphate is based on the molybdate: malachite green assay (Promega). Data are expressed as the number of picomolar of phosphate released per minute per milligram of protein. 


\section{Data analysis}

Data are presented as the mean \pm s.E.M., which represents three independent experiments. Statistical differences among groups were examined using ANOVA.

\section{Results}

\section{Inhibition of apo Al gene expression by CsA}

CsA is known to induce hyperlipidemia and dyslipoproteinemia with low concentrations of HDL (Wu et al. 1999). Therefore, we hypothesize that CsA can reduce serum apo AI concentrations. To test this possibility, we used a rat model created by s.c. injection of CsA for 7 days. Western-blot analysis showed that CsA-treated rats had significantly lower levels of apo AI than control rats (Fig. 1A). Apo AI can be synthesized in the liver followed by secretion into the bloodstream. Therefore, the observed reduction in serum apo AI protein could result from either inhibition of secretion or apo AI gene expression or both. Therefore, we measured apo AI mRNA levels in liver tissues using semi-quantitative RT-PCR. Our results showed that apo AI mRNA levels were significantly lower in CsA-treated rats than in controls (Fig. 1B). This was subsequently confirmed using northern-blotting analysis, in which the reduction of apo AI mRNA levels reached up to $29 \pm 5 \%$ compared with the controls $(n=5, P<0 \cdot 01)$. This finding was consistent with the observed reduction in serum apo AI protein. Our data, therefore, suggested that CsA inhibited gene expression of apo AI. However, no significant change in total cholesterol, triglycerides, and HDL-cholesterol was observed in the rats after 7 days (data not shown). This observation was consistent with the previous finding that short-term treatments with low doses of CsA have little influence on lipid profile in the rat (Andrade et al. 1993).

\section{Stimulation of apo Al gene expression by A23187 and its inhibition by CsA}

Our in vivo data suggested that CsA inhibits induction of the apo AI gene at the transcription level. The next question was how CsA inhibited apo AI gene transcription? It is known that various hormones and growth factors can regulate the expression of apo AI gene (Hargrove et al. 1999, Mooradian et al. 2004). CsA could inhibit apo AI gene expression through one of those identified mechanisms. To study the underlying mechanism, we took advantage of human hepatoma, Hep G2 cells, because this cell line has been widely utilized in apo AI gene research (Herbomel et al. 1984, Murao et al. 1998, Sakai et al. 2000). In our previous studies, we established the stably transfected Hep G2
A
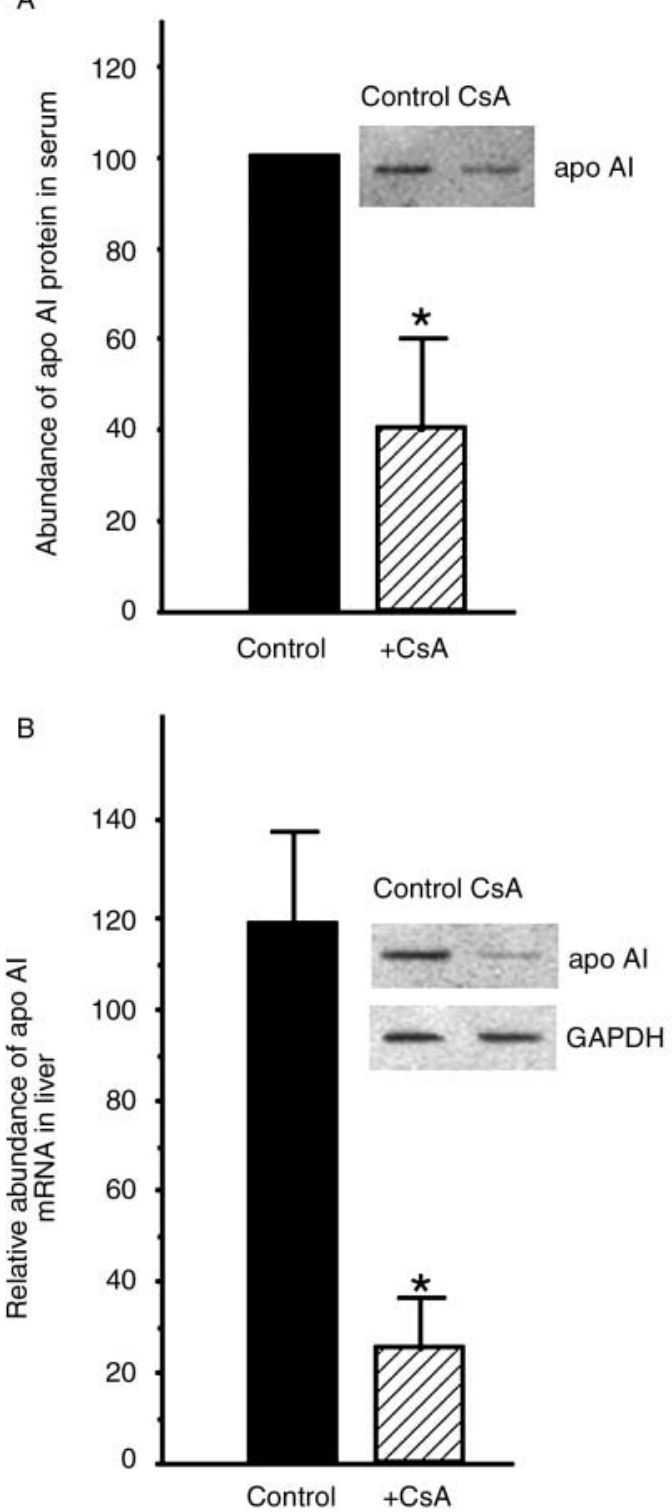

Figure 1 Cyclosporin A reduces apo Al protein levels in vivo. SD rats were injected with CsA for 7 days as described in Materials and methods. (A) Apo Al in serum measured using western blot (insert). The $y$-axis shows apo Al abundance relative to control rats. (B) Apo Al mRNA expression in rat liver tissue measured using semi-quantitative RT-PCR. PCR products were analyzed and visualized via agarose gel electrophoresis (insert). The $y$-axis is the relative abundance of apo Al mRNA compared with the level of GAPDH. *Significant difference when compared with the control $(n=5, P<0.01)$.

cells harboring an apo AI-474-CAT reporter gene (Zheng et al. 2000), and identified that epidermal growth factor (EGF) stimulates apo AI gene expression. Therefore, we first examined whether CsA inhibits apo AI gene activation induced by EGF 
(100 ng/ml). As shown in Fig. 2, EGF-induced apo AI gene activation was not inhibited by CsA ( $1 \mu \mathrm{M}$; Fig. 2$)$. Furthermore, CsA did not affect apo AI gene expression induced by PKC or PKA activation as we previously reported (Zheng et al. 2000, 2001; data not shown), suggesting that CsA inhibition was through a novel pathway.

CsA is well known to inhibit calcineurin, a protein phosphatase activated by calcium/calmodulin (Flanagan et al. 1991). Activation of calcineurin stimulates the gene transcription through its dephosphorylation and activation of various transcription factors. Therefore, it is conceivable that activation of calcineurin stimulates apo AI gene expression and CsA inhibits apo AI gene through inhibiting calcineurin. If this is the case, the increase of intracellular calcium will induce apo AI gene activation, and CsA, a calcineurin inhibitor, will block the induction of apo AI gene. As shown in the literature, high levels of intracellular calcium induced by A23187, a calcium ionophore, stimulate calcineurin and induce expression of various genes (Tsuboi et al. 1994, Schaefer et al. 1996, Crabtree 2001). Therefore, we examined the effects of A23187 on apo AI gene expression. As predicted, treatment of stable Hep G2 cells with $1 \mu \mathrm{M}$ A23187 for $24 \mathrm{~h}$ significantly stimulated apo AI gene activity as indicated by CAT activity (Fig. 2), and the stimulation of apo AI gene expression was timedependent (Fig. 3). Six-hour treatment induced a significant activation of apo AI gene promoter. Pretreatment of stable Hep G2 cells with actinomycin $\mathrm{D}$, a gene transcription inhibitor, completely abolished the induction of apo AI gene by A23187 (data not shown), further supporting that activation of apo AI gene by A23187 is through transcriptional events. Importantly, CsA treatment prevented A23187 from stimulating the apo AI gene (Figs 2 and 3), suggesting the involvement of calcineurin in apo AI gene regulation. To confirm this, we measured the levels of endogenous apo AI protein within cells and in the culture medium in response to various treatments. As anticipated, A23187 increased apo AI in cells and culture medium as well, and this stimulation was inhibited by pretreatment with CsA (Fig. 2C). Taken together, our data have suggested a novel mechanism for stimulation of apo AI gene expression involving activation of calcineurin, and also suggested that CsA inhibits apo AI gene expression through inhibiting the calcineurin pathway.

If CsA indeed inhibits apo AI gene expression through calcineurin inhibition, the inhibition of calcineurin by other calcineurin inhibitors should also inhibit apo AI gene expression. Therefore, we used the same approach to examine the effects of FK506, another calcineurin inhibitor with a different structure compared with CsA. As expected, pretreatment of stable Hep G2 cells with FK506 $(1 \mu \mathrm{M})$ also inhibited A23187-induced apo AI gene stimulation (Fig. 4). However, A23187-induced apo AI gene expression was not affected by rapamycin $(1 \mu \mathrm{M})$, another immunosuppressive agent (data not shown). Finally, we measured the phosphatase activity of calcineurin in Hep G2 cells in the presence of CsA, FK506, or rapamycin. As anticipated, our data in Fig. 5 showed that CsA and FK506, but not rapamycin, inhibited the activities of calcineurin phosphatase, providing a further correlation between reduction of apo AI expression and inhibition of calcineurin activity. In summary, our data indicate that the calcineurin pathway is involved in apo AI gene expression and CsA inhibits apo AI gene expression through inhibiting calcineurin.
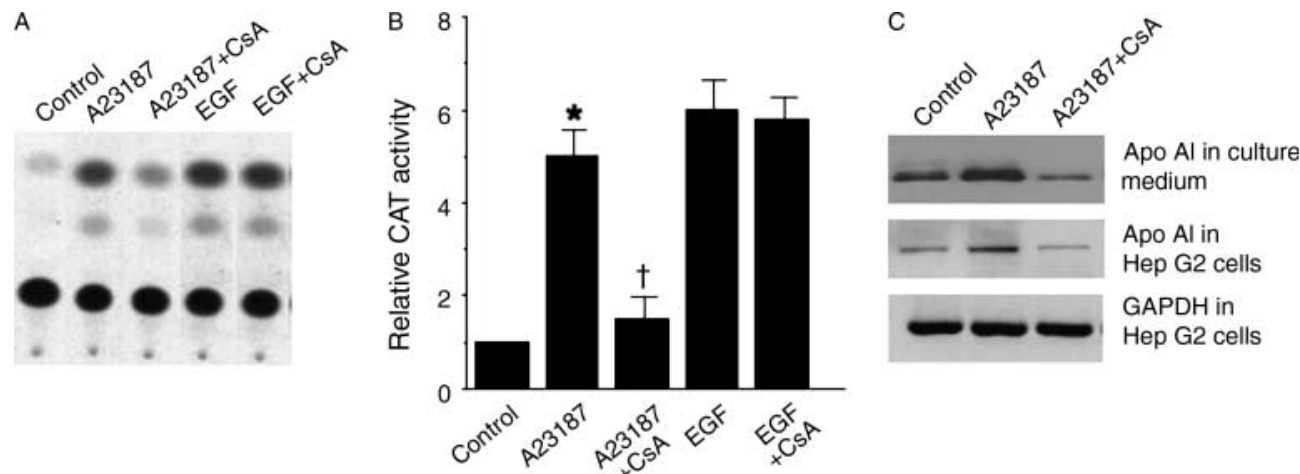

Figure 2 Cyclosporin A selectively inhibits A23187-stimulated apo Al gene expression. (A) Stable Hep G2 cells harboring an apo Al-474-CAT reporter gene were treated with A23187 or EGF in the presence or absence of CsA for $24 \mathrm{~h}$, followed by analysis of CAT activity. (B) The relative CAT activities ( $y$-axis) were standardized using the control. *Significant difference when compared with the control $(n=6, P<0.01)$. ${ }^{\dagger}$ Significant difference when compared with the group treated with $\mathrm{A} 23187$ alone $(n=6, P<0 \cdot 01)$. (C) A representative western-blot analysis of apo Al protein in the lysates and corresponding culture medium of Hep G2 cells exposed to A23187 and EGF with and without CsA. 


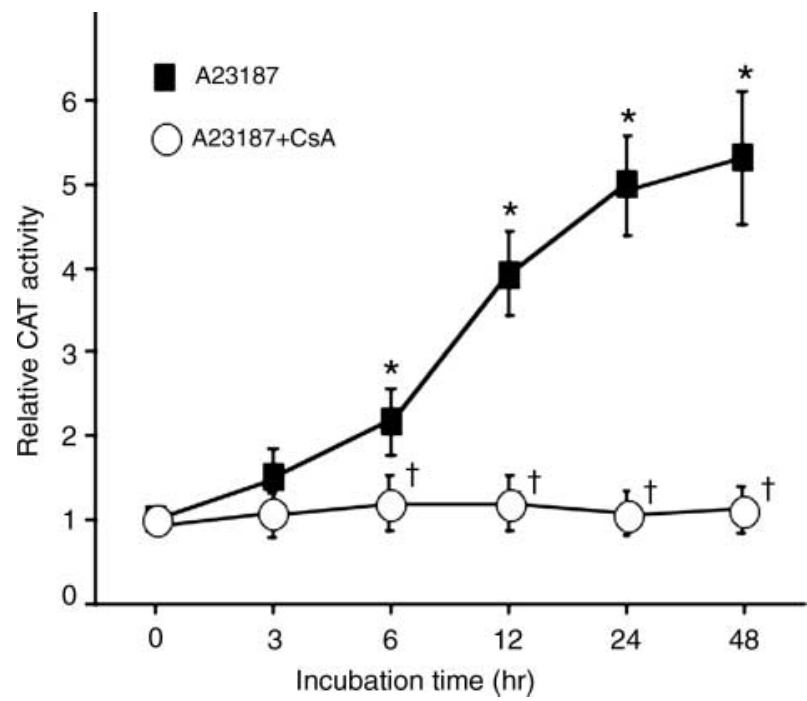

Figure 3 Time-dependent induction of apo Al gene expression by A23187 is inhibited by cyclosporin A. Stable Hep G2 cells harboring an apo Al-474-CAT reporter gene were treated with A23187 in the presence or absence of CsA for different times ( $x$-axis). Apo Al gene promoter activity was indicated by the relative CAT activities ( $y$-axis). *Significant difference when compared with the 0 -h point $(n=5, P<0 \cdot 01)$. ${ }^{\dagger}$ Significant difference when compared with the group treated with A23187 alone at the specific time-point $(n=6, P<0.01)$.

\section{Discussion}

In this report, our data indicated that CsA inhibited apo AI gene expression both in vivo and in vitro. We have also provided evidence that intracellular calcium mobilization stimulated apo AI gene expression and that CsA inhibited apo AI gene expression through inhibiting the calcium/ calmodulin-dependent calcineurin pathway.
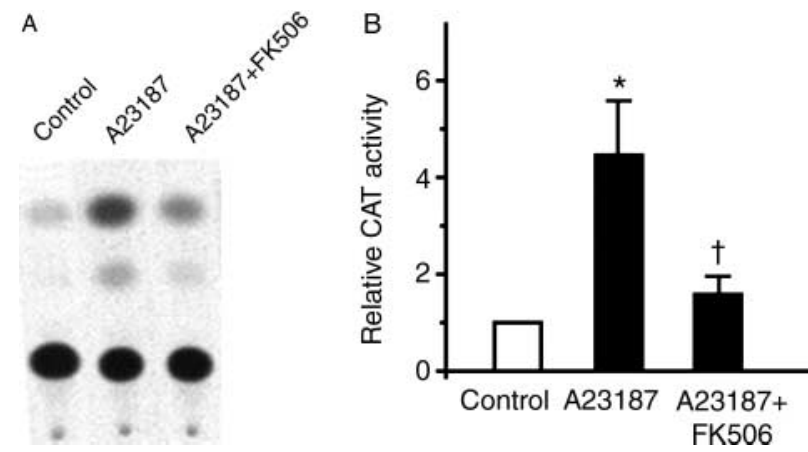

Figure 4 The calcineurin inhibitor FK506 inhibits A23187-induced apo Al gene expression. (A) Stable Hep G2 cells harboring an apo Al-474-CAT reporter gene were treated with A23187 in the presence or in the absence of FK506 for $24 \mathrm{~h}$, followed by analysis of CAT activity. (B) The relative CAT activities ( $y$-axis) were standardized using the control. *Significant difference when compared with the control $(n=5, P<0.01)$. ${ }^{\dagger}$ Significant difference when compared with the group treated with A23187 alone $(n=5$, $P<0.01)$.

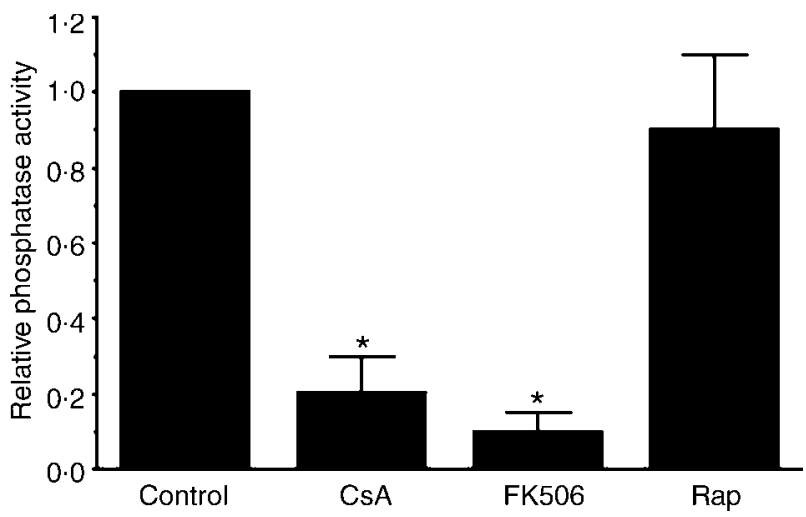

Figure 5 CsA and FK506 inhibit calcineurin phosphatase activity in Hep G2 cells. Cultured Hep G2 cells were lysed by repeated freezing and thawing as described in Materials and methods. The released phosphate was detected using the molybdate:malachite green assay. The relative phosphatase activity was defined by dividing each value for the phosphatase activity $(\mathrm{pmol} / \mathrm{min}$ per $\mathrm{mg}$ ) of treated Hep G2 cells by that of untreated cells. Rap, rapamycin. *Significant difference when compared with the control $(n=5, P<0 \cdot 01)$.

Apo AI is an important functional constitute of HDL particles, which are key to transfer of excess peripheral cholesterol to the liver for disposal. Increasing evidence indicates that activation of various intracellular signaling pathways stimulates apo AI gene expression, but it is not completely understood which pathway, if inhibited, will contribute to the reduction of apo AI in vivo. CsA as an immunosuppressive drug has been widely used in organ transplant patients and other conditions as well. Unfortunately, CsA induces significant hyperlipidemia, and its use is associated with increased atherosclerotic disease. CsA, a calcineurin inhibitor, was found to form a complex with ciclophilin to bind calcineurin (Colgan et al. 2005). However, it is not clear how calcineurin inhibition by CsA contributes to the development of atherosclerosis. Our data have shown that 7-day treatment with CsA reduces apo AI gene expression as indicated by the reduction of serum apo AI concentrations and apo AI mRNA levels in liver tissues. Since a low HDL-cholesterol is a significant independent cardiovascular risk factor, this mechanism has powerful clinical implications.

Through investigation of the underlying mechanisms, we have found that calcium mobilization as a novel mechanism stimulates apo AI gene expression and this pathway is inhibited by CsA, a calcineurin inhibitor. We previously identified that growth factors and hormones, such as EGF and insulin, can stimulate apo AI gene expression (Murao et al. 1998, Zheng et al. 2001). We also showed that activation of PKA or PKC can upregulate apo AI gene expression through activation of the Sp1-transcription factor (Zheng et al. 
2000). These mechanisms identified in vitro could contribute to the in vivo regulation of apo AI gene activity. However, CsA inhibits apo AI gene transcription in vivo, but does not affect the EGF-induced apo AI gene expression in Hep G2 cells, suggesting that EGF-induced apo AI expression, if present in vivo, may not be inhibited by CsA. Instead, CsA inhibits the stimulation of apo AI by A23187, suggesting that calcium mobilization-induced apo AI gene activation could be a mechanism present both in vitro and in vivo. Therefore, our finding that calcium stimulates apo AI gene expression may open a new avenue to develop clinical approaches to increase serum apo AI protein levels.

In addition, A23187, a calcium ionophore, is known to stimulate calcineurin in various cell systems (Tsuboi et al. 1994, Schaefer et al. 1996, Crabtree 2001). Activation of calcineurin stimulates the gene transcription through dephosphorylating various transcription factors (Crabtree 2001). Therefore, that A23187-induced apo AI gene expression was inhibited by the calcineurin inhibitors (Flanagan et al. 1991), CsA and FK506, strongly suggests that calcineurin is a key molecule that stimulates apo AI gene expression in vivo. Although more studies will be required to elucidate how calcineurin induces apo AI gene activity, our data have pointed to a direction in which to develop drugs to activate liver and intestinal calcineurin to increase apo AI production.

In summary, our results have provided evidence that CsA inhibits apo AI gene expression through inhibition of the calcineurin pathway. We have also identified a novel mechanism for apo AI gene expression involving the activation of calcium/calmodulin-dependent calcineurin. These studies should lead to a newer focus on HDL metabolism in patients treated with CsA. However, it is still unclear whether and how physiological stimuli activate the calcium/calmodulin-dependent calcineurin pathway to upregulate apo AI gene expression in vivo. In addition, the signaling mechanism(s) at the downstream of calcineurin, including the transcription factor(s) and the response element(s), has not been determined. Therefore, more studies will be required for further clarification.

\section{Acknowledgements}

This work was supported by Canadian Institute of Health Research (CIHR) operating grants (N C W W and X L Z). We thank Catherine Diao for technical assistance. The authors declare that there is no conflict of interest that would prejudice the impartiality of this scientific work.

\section{References}

Andersson LO 1997 Pharmacology of apolipoprotein A-I. Current Opinion in Lipidology 8 225-228.
Andrade RJ, Lucena MI, Gonzalez-Correa JA, Garcia-Arias C \& GonzalezSantos P 1993 Short-term effect of various doses of cyclosporin A on plasma lipoproteins and its distribution in blood: an experimental study. Human and Experimental Toxicology 12 141-146.

Ballantyne CM, Podet EJ, Patsch WP, Harati Y, Appel V, Gotto AM Jr \& Young JB 1989 Effects of cyclosporine therapy on plasma lipoprotein levels. Journal of the American Medical Association 262 53-56.

Barter PJ \& Rye KA 1996a High density lipoproteins and coronary heart disease. Atherosclerosis 121 1-12.

Barter PJ \& Rye KA 1996b Molecular mechanisms of reverse cholesterol transport. Current Opinion in Lipidology 7 82-87.

Brouillette CG \& Anantharamaiah GM 1995 Structural models of human apolipoprotein A-I. Biochimica et Biophysica Acta 1256 103-129.

Colgan J, Asmal M, Yu B \& Luban J 2005 Cyclophilin A-deficient mice are resistant to immunosuppression by cyclosporine. Journal of Immunology 174 6030-6038.

Crabtree GR 2001 Calcium, calcineurin, and the control of transcription. Journal of Biological Chemistry 276 2313-2316.

Dobiasova M \& Frohlich J 1998 Understanding the mechanism of LCAT reaction may help to explain the high predictive value of LDL/HDL cholesterol ratio. Physiological Research 47 387-397.

Dunn SE, Chin ER \& Michel RN 2000 Matching of calcineurin activity to upstream effectors is critical for skeletal muscle fiber growth. Journal of Cell Biology 151 663-672.

Fielding CJ \& Fielding PE 1995 Molecular physiology of reverse cholesterol transport. Journal of Lipid Research 36 211-228.

Flanagan WM, Corthesy B, Bram RJ \& Crabtree GR 1991 Nuclear association of a T-cell transcription factor blocked by FK-506 and cyclosporin A. Nature 352 803-807.

Gui Y \& Zheng XL 2003 Epidermal growth factor induction of phenotype-dependent cell cycle arrest in vascular smooth muscle cells is through the mitogen-activated protein kinase pathway. Journal of Biological Chemistry 278 53017-53025.

Hargrove GM, Junco A \& Wong NC 1999 Hormonal regulation of apolipoprotein AI. Journal of Molecular Endocrinology 22 103-111.

Herbomel P, Bourachot B \& Yaniv M 1984 Two distinct enhancers with different cell specificities coexist in the regulatory region of polyoma. Cell 39 653-662.

Klee CB, Ren H \& Wang X 1998 Regulation of the calmodulinstimulated protein phosphatase, calcineurin. Journal of Biological Chemistry 273 13367-13370.

Kuster GM, Drexel H, Bleisch JA, Rentsch K, Pei P, Binswanger U \& Amann FW 1994 Relation of cyclosporine blood levels to adverse effects on lipoproteins. Transplantation 57 1479-1483.

Le Goff W, Peng DQ, Settle M, Brubaker G, Morton RE \& Smith JD 2004 Cyclosporin A traps ABCA1 at the plasma membrane and inhibits ABCA1-mediated lipid efflux to apolipoprotein A-I. Arteriosclerosis, Thrombosis, and Vascular Biology 24 2155-2161.

Lopez-Miranda J, Perez-Jimenez F, Torres A, Espino-Montoro A, Gomez P, Hidalgo-Rojas L, Ordovas JM \& Jimenez-Pereperez JA 1992 Effect of cyclosporin on plasma lipoproteins in bone marrow transplantation patients. Clinical Biochemistry 25 379-386.

Luoma PV 1997 Gene activation, apolipoprotein A-I/high density lipoprotein, atherosclerosis prevention and longevity. Pharmacology and Toxicology 81 57-64.

Miller NE, La Ville A \& Crook D 1985 Direct evidence that reverse cholesterol transport is mediated by high-density lipoprotein in rabbit. Nature 314 109-111.

Mooradian AD, Haas MJ \& Wong NC 2004 Transcriptional control of apolipoprotein A-I gene expression in diabetes. Diabetes $\mathbf{5 3}$ 513-520.

Murao K, Wada Y, Nakamura T, Taylor AH, Mooradian AD \& Wong NC 1998 Effects of glucose and insulin on rat apolipoprotein A-I gene expression. Journal of Biological Chemistry 273 18959-18965.

Ness GC, Lopez D, Chambers CM, Newsome WP, Cornelius P, Long CA \& Harwood HJ Jr 1998 Effects of L-triiodothyronine and the thyromimetic L-94901 on serum lipoprotein levels and hepatic low- 
density lipoprotein receptor, 3-hydroxy-3-methylglutaryl coenzyme A reductase, and apo A-I gene expression. Biochemical Pharmacology 56 121-129.

Romney JS, Chan J, Carr FE, Mooradian AD \& Wong NC 1992 Identification of the thyroid hormone-responsive messenger RNA spot 11 as apolipoprotein-A1 messenger RNA and effects of the hormone on the promoter. Molecular Endocrinology 6 943-950.

Rubin EM, Krauss RM, Spangler EA, Verstuyft JG \& Clift SM 1991 Inhibition of early atherogenesis in transgenic mice by human apolipoprotein AI. Nature 353 265-267.

Sakai T, Jin FY, Kamanna VS \& Kashyap ML 2000 Albumin inhibits apolipoprotein AI and AII production in human hepatoblastoma cell line (Hep G2): additive effects of oleate-albumin complex. Atherosclerosis 149 43-49.

Schaefer A, Magocsi M, Stocker U, Fandrich A \& Marquardt H 1996 $\mathrm{Ca}^{2+} /$ calmodulin-dependent and -independent down-regulation of c-myb mRNA levels in erythropoietin-responsive murine erythroleukemia cells. The role of calcineurin. Journal of Biological Chemistry 271 13484-13490.

Soyal SM, Seelos C, Lin-Lee YC, Sanders S, Gotto AM Jr, Hachey DL \& Patsch W 1995 Thyroid hormone influences the maturation of apolipoprotein A-I messenger RNA in rat liver. Journal of Biological Chemistry 270 3996-4004.

Tsuboi A, Muramatsu M, Tsutsumi A, Arai K \& Arai N 1994 Calcineurin activates transcription from the GM-CSF promoter in synergy with either protein kinase C or NF-kappa B/AP-1 in T cells. Biochemical and Biophysical Research Communications 199 1064-1072.

Wu J, Zhu YH \& Patel SB 1999 Cyclosporin-induced dyslipoproteinemia is associated with selective activation of SREBP-2. American Journal of Physiology 277 E1087-E1094.

Zheng XL, Matsubara S, Diao C, Hollenberg MD \& Wong NC 2000 Activation of apolipoprotein AI gene expression by protein kinase A and kinase $\mathrm{C}$ through transcription factor, Sp1. Journal of Biological Chemistry 275 31747-31754.

Zheng XL, Matsubara S, Diao C, Hollenberg MD \& Wong NC 2001 Epidermal growth factor induction of apolipoprotein A-I is mediated by the Ras-MAP kinase cascade and Sp1. Journal of Biological Chemistry 276 13822-13829.

Received in final form10 May 2006

Accepted 1 August 2006 